\section{Microscopic Analysis of Metal Recovered from the Wreck of RMS Titanic}

\author{
J.J. Hooper McCarty ${ }^{1}$ and T. Foecke $e^{1,2}$ \\ ${ }^{I}$ Department of Materials Science and Engineering, The Johns \\ Hopkins University, Baltimore, MD \\ ${ }^{2}$ Metallurgy Division, National Institute of Standards and \\ Technology, Gaithersburg, MD \\ tfoecke@nist.gov
}

\section{Titanic's Discovery}

On April 14, 1912, the RMS Titanic collided with an iceberg and sank in the North Atlantic, approximately 400 miles southeast of Newfoundland. Despite her double-bottom construction and series of water-tight compartments, the luxurious passenger liner, deemed 'unsinkable' by the popular press, sank in only two hours and 40 minutes, taking 1523 lives with her. As the largest man-made moving object of her time, the construction of the RMS Titanic was a technological feat, yet her sinking comprised one of the most famous disasters of the twentieth century. A colossal tragedy, the sinking has been shrouded in mystery ever since, and has led to unending speculation concerning the details of that fateful evening. Heightened interest has produced a plethora of books, films, and exhibitions in recent years, all probing an answer to the most intriguing question: How and why did the Titanic, believed to be man's technological triumph over nature, sink in less than three hours time. The search for forensic evidence to the ship's demise began nearly 20 years ago.

Since the 1985 discovery of the ship, scientists have questioned the role that structural materials played in the sinking. Early studies focused on the quality of the hull steel as a contributor to the ship's rapid sinking, but experimental results showed that the material was 'state of the art' for 1911. Instead, it was suggested that the quality of the wrought iron rivets may have been an important factor in the opening of the steel plates during flooding. Here we report on the microscopic examination of the rivet materials that went into the building of Titanic.

\section{The Ship's Construction}

Titanic was constructed from several thousand $1 \frac{1 / 2 \text {-inch }}{2}$ thick steel plates and approximately 3,000,000 rivets made of both wrought iron and steel. Wrought iron is very pure iron (less than

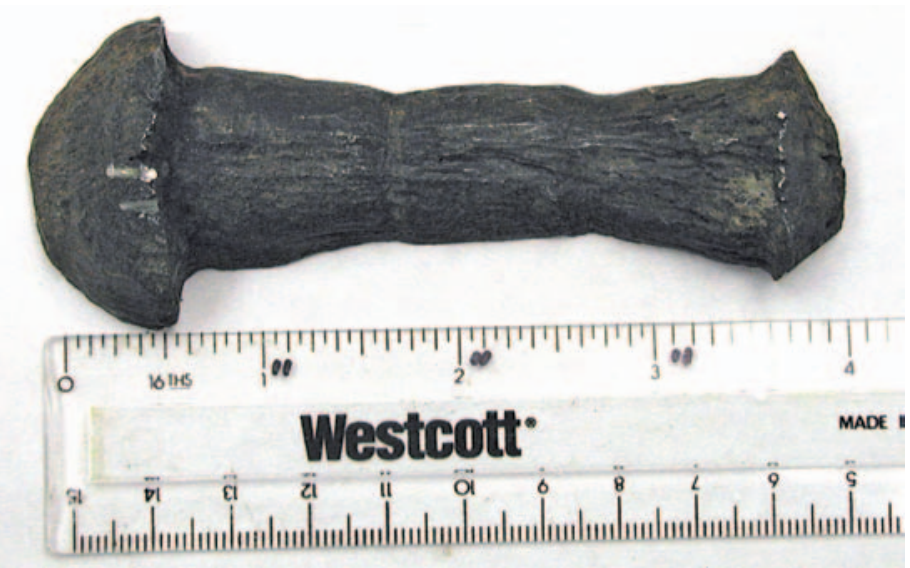

Figure 1: A macro photo of a hull rivet recovered from the wreck site. It shows a "woody" appearance due to the ferrite being corroded away, leaving ridges of slag. The right end head of the rivet has popped off, leaving a residue of the inside of the head.

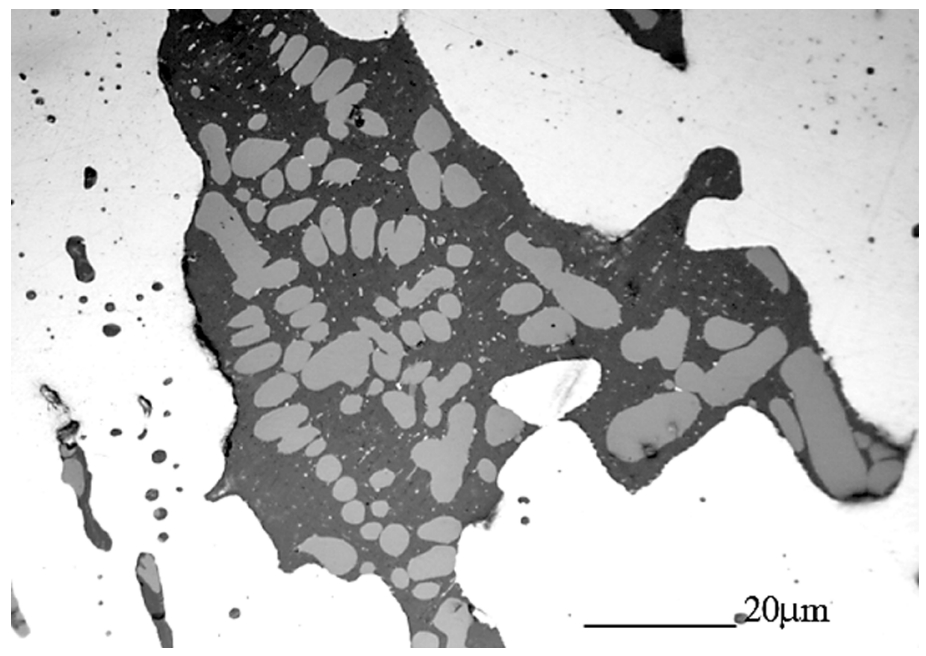

Figure 2: A large slag particle containing dendritic crystals of iron that precipitated from the iron-silicate slag solution during cooling. Optical micrograph taken at $500 \mathrm{X}$.

$0.02 \mathrm{wt} \%$ carbon) containing approximately $2-3 \mathrm{wt} \%$ of slag (iron silicate) inclusions. Late $19^{\text {th }} /$ early $20^{\text {th }}$ century wrought iron was produced by the puddling process, a method that required the puddler, or stirrer, to constantly agitate a molten charge of iron and slag. This process provided a method of refining the wrought iron, but was very dependent on the skill of the puddler working the charge. For centuries, wrought iron was used for applications requiring resistance to fatigue-failure and corrosion, as well as formability and machinability [1]. Yet, by the 1960s, the strength, ease of production and corrosion resistance of steel alloys had taken over, and items advertised today as "wrought iron" are actually made of mild steel.

Rivets are produced from bars cut from extruded cylindrical rods (figure 1). Sections of rods are heated in the shop and a single head is formed in a die. In a 1911 shipyard, these partial rivets were re-heated to red hot in a coal-fueled stove, and thrown to a riveting gang, who quickly inserted the rivet into the plate hole, and hammered a second head from the protruding shaft. Rivets form a watertight joint via compressive stresses that form as the rivet cools and contracts after it is hammered into place.

Published results of tensile tests on mid- $20^{\text {th }}$ century rolled wrought iron report a yield strength that is 1.5 times higher in the longitudinal direction (with respect to the rolling direction) than in the transverse direction (orthogonal to the rolling direction). In addition, wrought iron was found to possess more than twice the ductility along the rolling direction [2]. This variation in mechanical properties can have a detrimental effect on a wrought iron rivet's strength in structural applications if the orientation of the slag inclusions is not considered.

\section{Metallography}

Data from 35 Titanic rivets are shown here-21 from the bulkheads, six from the hull, three from the deck and two from the portholes. To complete the examination of these rivets alone, over 40,000 images were taken and quantitatively analyzed.

In order to characterize the wrought iron microstructure, a cross-section of each rivet was polished to a $0.05 \mu \mathrm{m}$ surface finish, and several hundred to several thousand digital gray-scale images were taken of each rivet at 100X using an optical microscope. Each image captured an area of $2 \mathrm{~mm}^{2}$, and had a resolution of $1600 \times 1200$ pixels. These digital images were combined to create a cross-sec- 


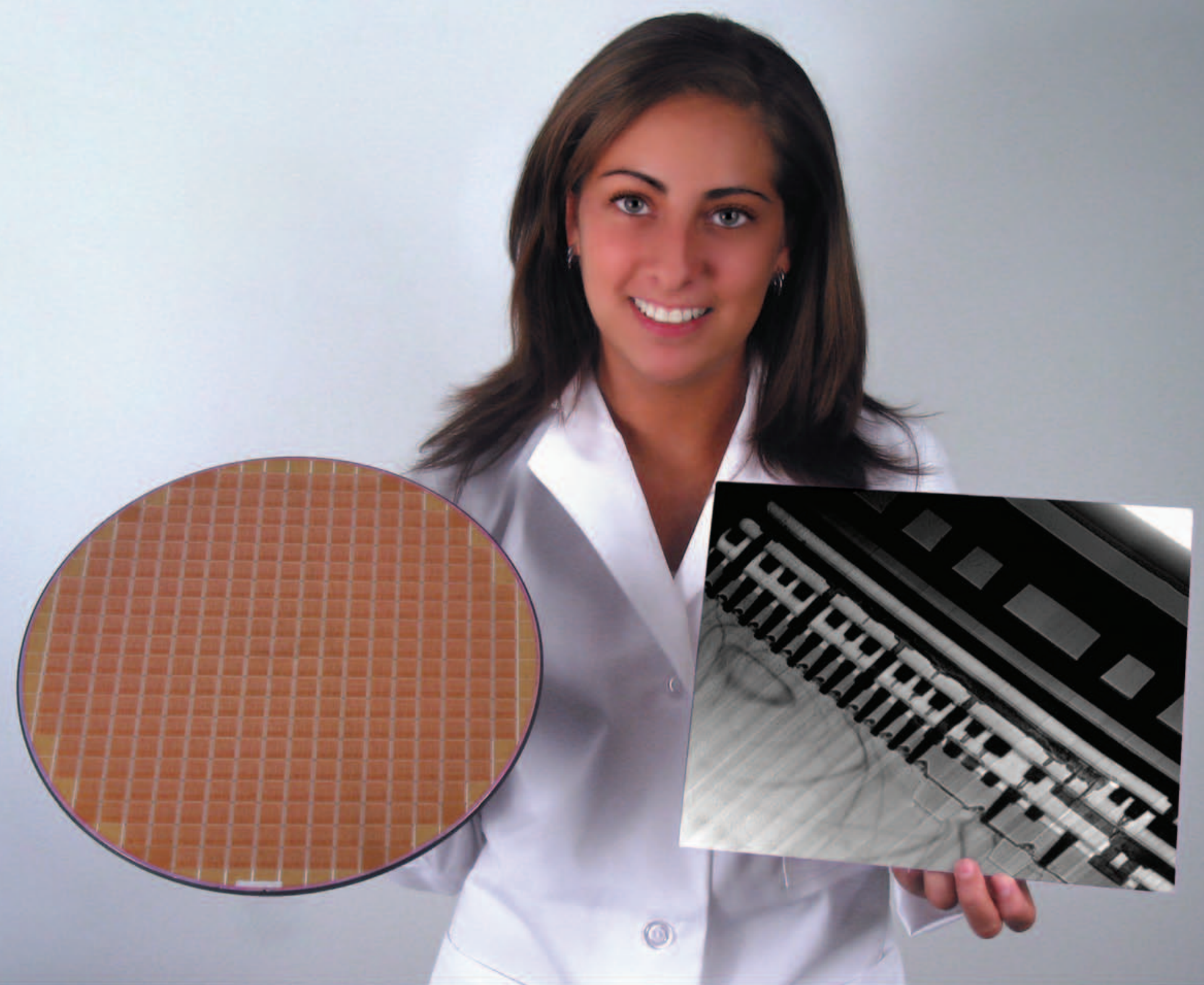

\section{Go from WAFER to RESULTS faster}

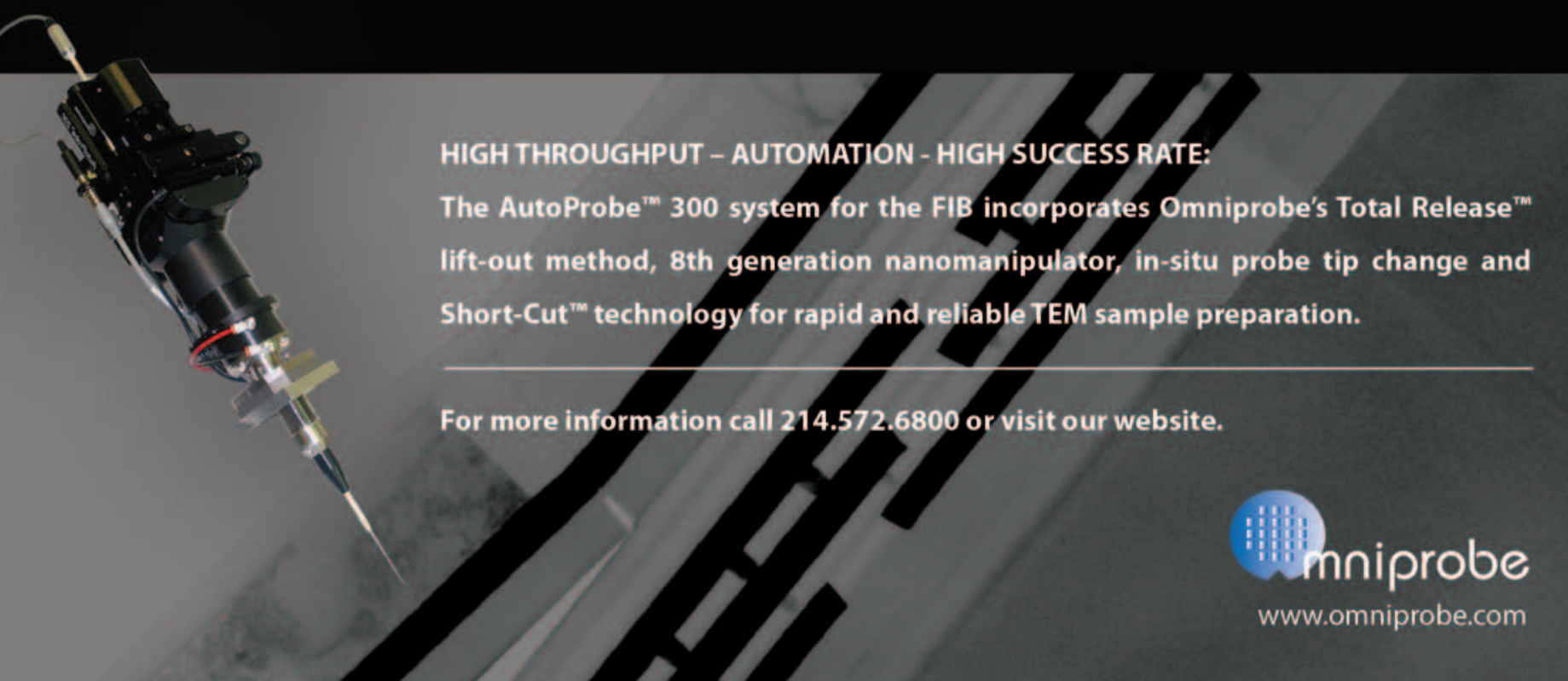




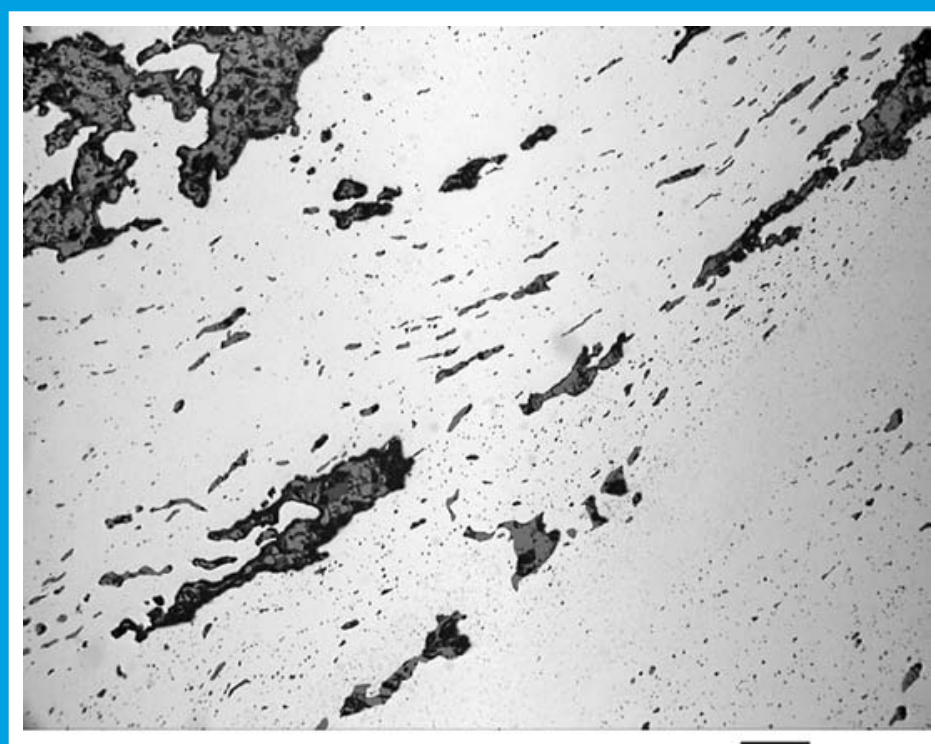

Figure 3: Optical micrographs of Titanic wrought iron indicate considerable variability in the microstructure among rivets. In this micrograph, large slag particles are seen to follow the direction of flow during formation of the rivet head. Bar $=50 \mu \mathrm{m}$

tional mosaic of each rivet. The microstructures within each image were then quantified using an analysis routine that measured specific slag particle parameters. The analysis was completed with a routine written in NIH Image, which identified each particle through a comparison of gray-scale values and set an appropriate threshold to capture each slag particle present. Additional images were acquired at higher magnifications to analyze qualitative characteristics such as the interfaces between iron and slag, and dendritic phase transformations within slag particles.

\section{Was there too much slag?}

Optical microscopy revealed that the wrought iron rivets varied significantly in slag content and slag particle size. In addition, huge variations in the slag area percent, aspect ratio, and orientation were seen within each rivet, as evidenced by image analysis results from thousands of micrographs. The area percent of slag was as high as $20 \%$ in some regions, and the aspect ratio of large particles was found to be as high as 20. A number of micrographs revealed slag particles that were so large; they contained formations of dendritic crystal phases that had precipitated out of the iron-silicate solution during cooling. An example is shown in Figure 2.

In comparison, sources of turn-ofthe-century wrought iron, long, large stringers were typically broken up using a process known as piling. Piling required the stacking of puddled wrought iron bars in a grid pattern, reheating it and rolling it again in order to break up the remaining aligned stringers. This piling operation created more uniform iron with smaller, more evenly disbursed, slag particles. In
Victorian England (mid-19th to 20th c.), the piling process was a measure of the quality of the wrought iron, since a larger number of pilings improved the mechanical properties [3,4]. Rivet bar was typically of "best-best-best" quality, that is, it had been piled three times [5].

\section{How were the rivets installed?}

Image analysis revealed that in the heads of the rivets, which were hammered in place, slag is oriented perpendicular to the rivet shaft, or tensile axis. The slag particles run parallel to the rivet shaft due to extrusion while hot, which correlates with high tensile strength and ductility along the rivet shaft. Microscopy also revealed unbroken slag stringers in the rivet heads running perpendicular to the shaft, confirming that the heads were also formed while the rivet was hot. Note in Figure 3, how the slag within a Titanic rivet is oriented in a $90^{\circ}$ turn, reflecting the effects of hammering a rivet head in place. This corresponds to what we know about early $20^{\text {th }}$ century riveting procedures, where a rivet was driven and a head was hammered in place while still hot. (polished 100x image) Figure 4 shows results of image analysis from thousands of images in the cross-sectional mosaics of two Titanic hull rivets, indicating that the reorientation of slag stringers, which was found in all rivets, occurs independently of composition. (color plot)

\section{What happens under load?}

Several small tensile specimens were sequentially loaded to various strain levels prior to fracture, and at each step the microstructures were analyzed and compared, both in-situ and ex-situ. Using a comparison of micrographs from the sequence, the deformation process was observed in a number of large slag particles at low strains. A series of optical micrographs taken at 400X are shown in Figure 5, detailing the early deformation process that occurs in longitudinally oriented wrought iron as it is strained in

$\theta$ (degrees)

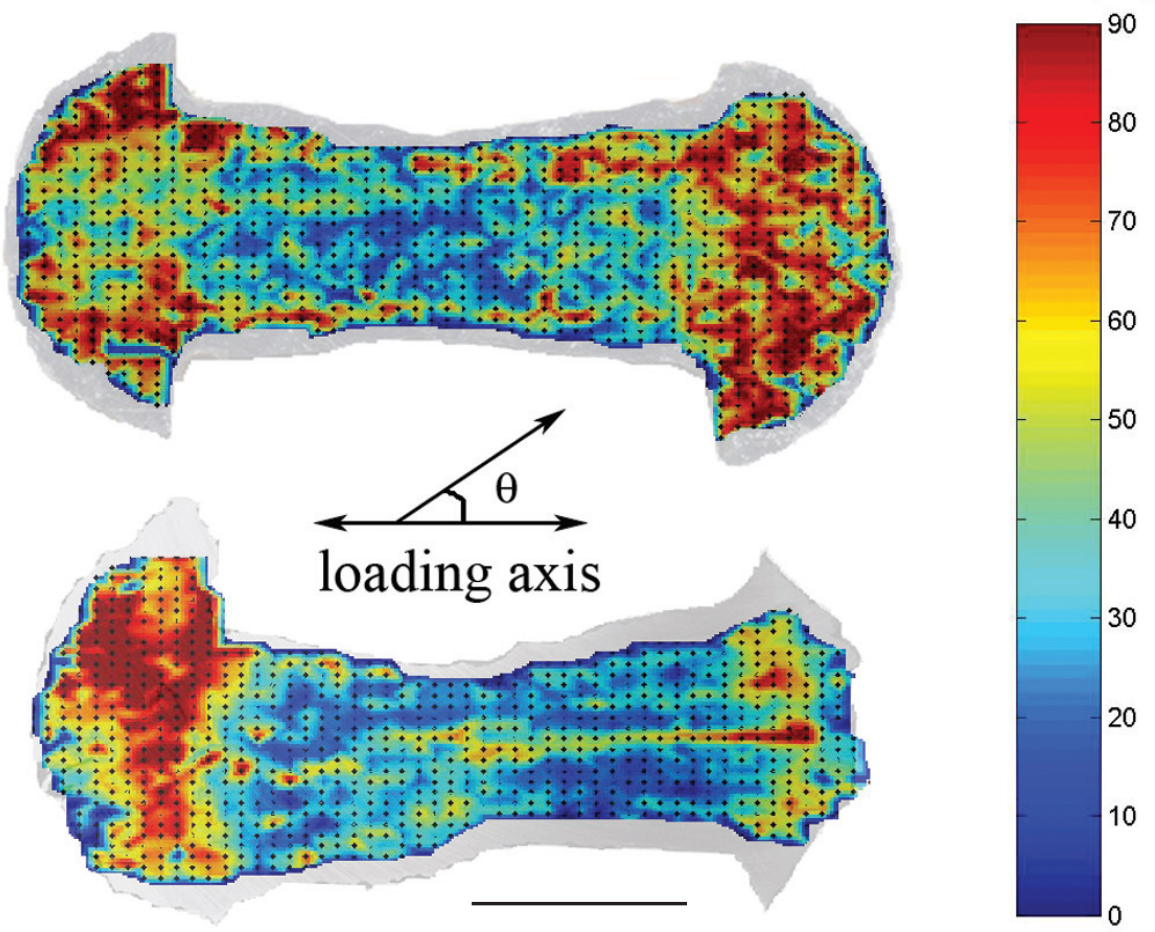

Figure 4: Image analysis of thousands of micrographs from various regions within the cross-section of two Titanic hull rivets shows the orientation of slag particles with respect to the rivet shaft. Note the high concentration of particles in the heads of the rivets oriented at $90^{\circ}$ (red) to the loading axis. Bar represents 1 inch $(2.54 \mathrm{~cm})$. 
The State of the Art, Revolutionary

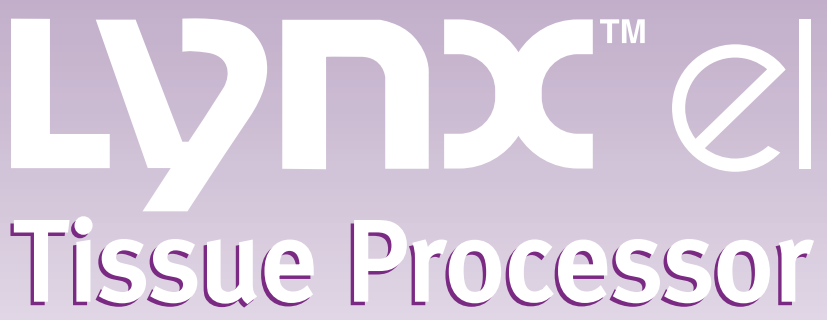

The EMS LMNX Automated Tissue Processor now made even better... for Electron Microscopy and Light Microscopy.

Dramatically reduce your sample preparation cost and time with improved reproducible results!!

The EMS LMNX allows for the processing of tissue all the way through $100 \%$ resin.

\section{Primary uses:}

- Ultrastructural Studies

- Extremely Hard Tissues - Undecalcified Bone

- High Resolution Light Microscopy

- Immunohistochemistry

- Dehydration for SEM

- Deparaffinization

- En-bloc Staining

\section{- And Much More}

This state of the art Automated Tissue Processor has many unique features making the unit the most versatile and reliable unit on the market at a very competitive price.

\section{Features:}

- Stainless Steel Working Surfaces

- Enclosed Benchtop Unit

- Reagent Turntable/ Max of 56 Specimens

- 20 Reagent Vials /Cycle

- Temp Range of $4^{\circ} \mathrm{C}-60^{\circ} \mathrm{C}$

- Built in Exhaust Fan

- Alarm Monitoring System

- Multiple Safety Features

- Battery Back Up

- Storage of 10 Programs/ Each with 20 Pre-programmable Steps

- Printer Output

- Delay Start of Programs

> And Much More...

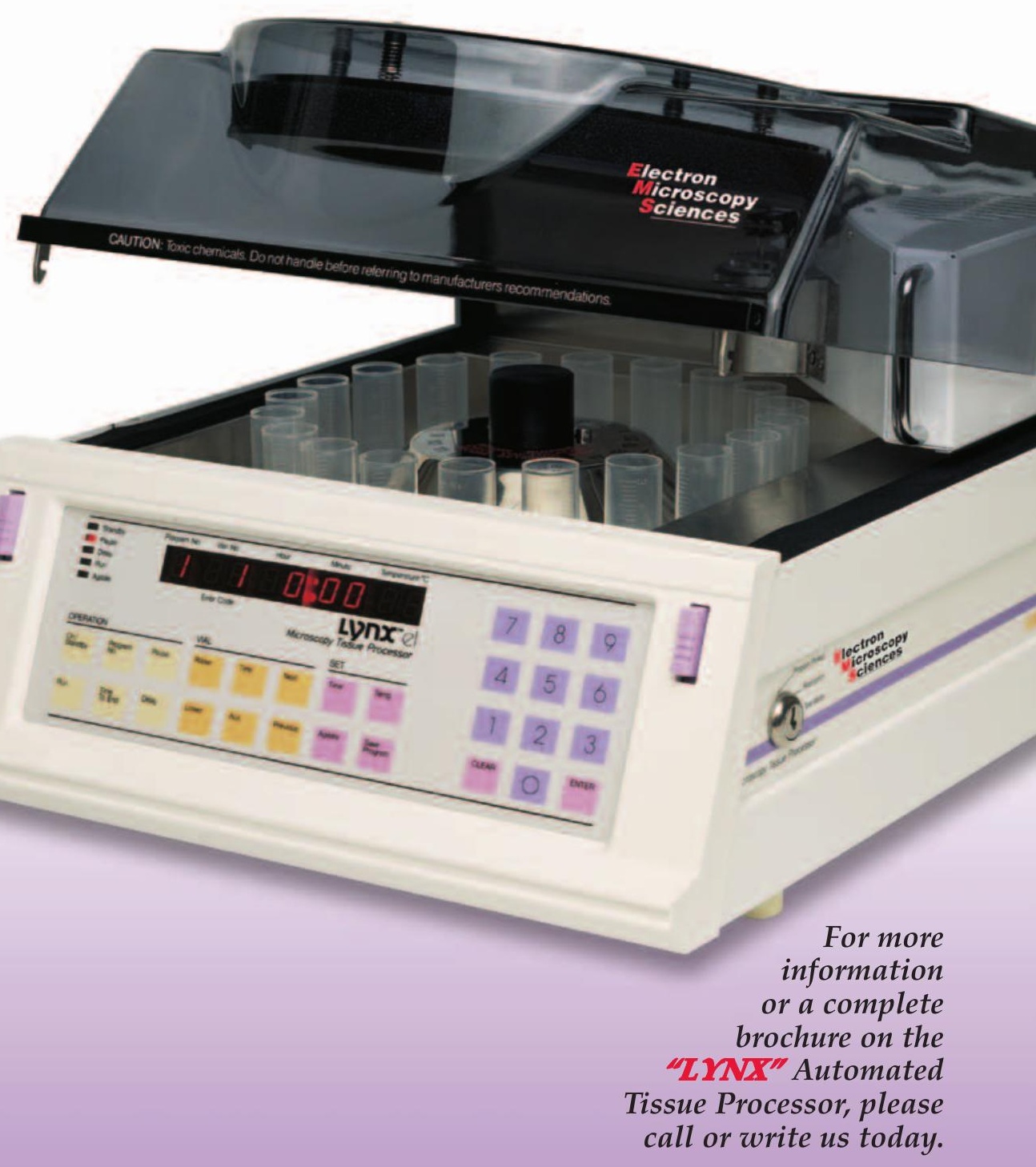

Electron Microscopy Sciences - 1560 Industry Road P.O. Box 550 - Hatfield, PA 19440 tel: 2 I5.4 I2.8400 - fax:2 I5.4 I2.8450 - email:sgkcck@aol.com • web:www.emsdiasum.com 


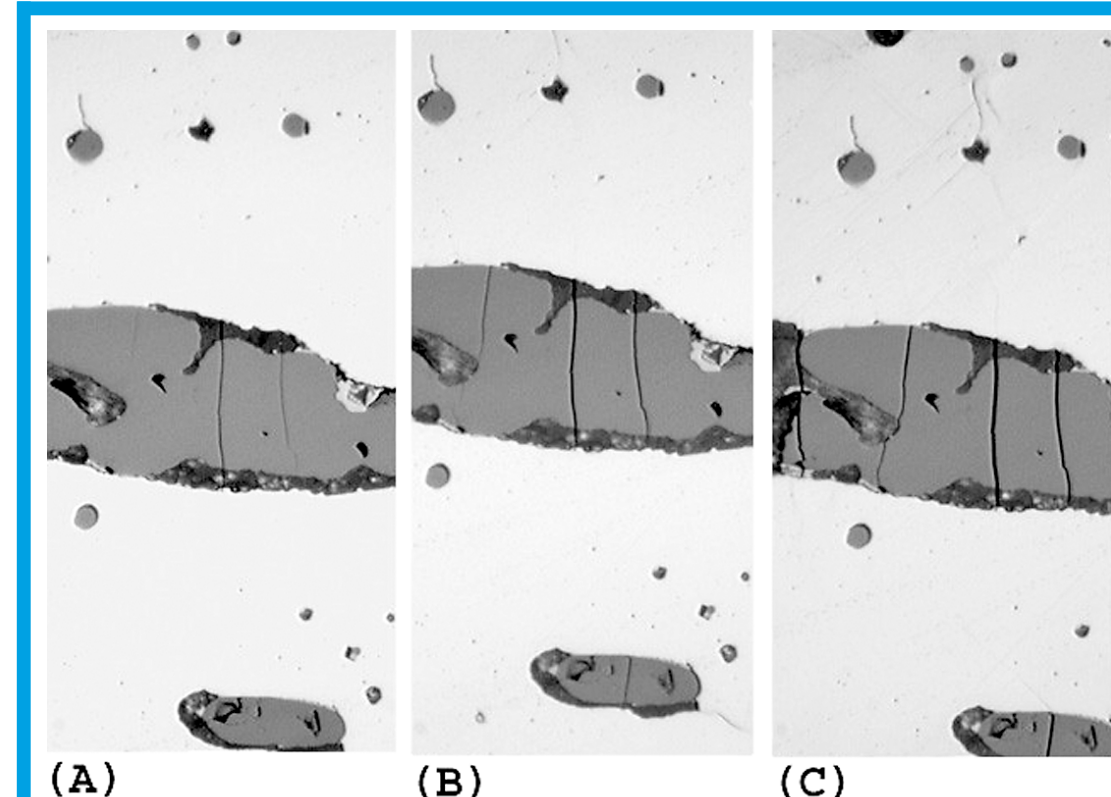

(A)

(B)

\section{(C)}

Figure 5. Optical micrographs showing the deformation of a slag particle in wrought iron when loaded along the extrusion direction. (a) At a total strain of $1.5 \%$ (b) $2.4 \%$ and (c) $3.8 \%$. Bar represents $20 \mu \mathrm{m}$.

approximately $1.5 \%$ increments. (a) With little ductility introduced into the samples, fine cracks formed across large, elongated slag particles. (b) As the strain increased, the initial cracks penetrated across slag particles. Fine secondary cracks were initiated, further subdividing large slag particles into smaller segments. (c) Small, nearly undetectable cracks were observed emanating from the slag

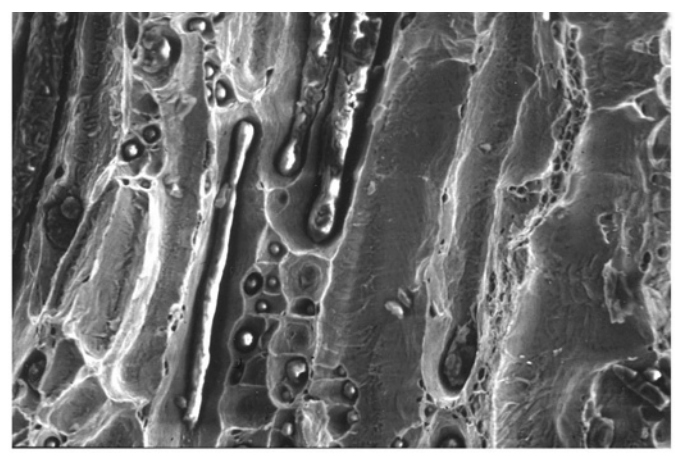

(A)

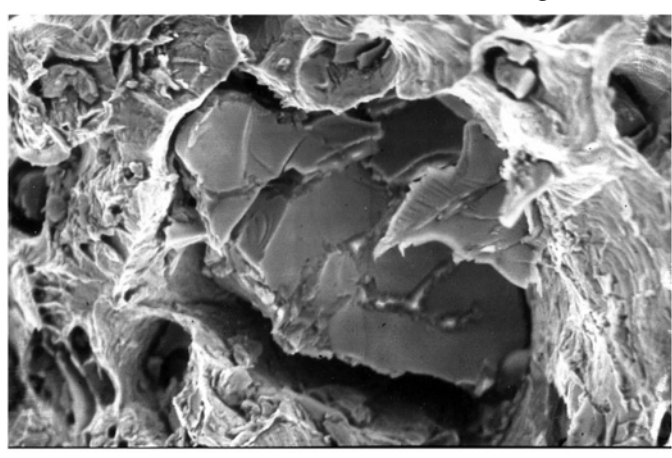

(B)
Figure 6. Optical micrographs showing the fractured surfaces of wrought iron tensile bars. (a) Microvoids formed around elongated slag particles suggest failure at iron-slag interface. (b) Cracking in a large slag particle confirms its brittle nature. Bars represent $10 \mu \mathrm{m}$.

into the iron matrix, eventually propagating and deforming along grain boundaries. Noticeably, surface roughness increased due to grain rotation. Localized regions of plasticity were seen around crack tips that have originated from within particles and have propagated into the matrix. Evidence of interfacial debonding was seen, in some cases the result of early cracking. In the later stages of yielding, slip bands are noted throughout the matrix, originating at both large and small particles.

Our in-situ and ex-situ sequential loading experiments revealed that the slag particles fracture prior to or nearly at the same time as the onset of yielding in the iron matrix, suggesting that the presence of large particles initiates the failure process in wrought iron. Eventually, the iron begins to yield and subsequently deform. The cracks in slag particles act to both nucleate and intensify the formation of slip bands within the sample, due to the presence of a stress concentration at the tip of the crack.

\section{Fractography}

The morphology of fractured surfaces further supports the hypothesis that the slag particles act as sites for stress concentrations under loading. Surfaces were analyzed post-tensile testing using the scanning electron microscope in secondary electron mode at $20 \mathrm{kV}$. SEM images show evidence for the separation at the interface between slag and iron-the larger the particle, the larger the interfacial area. In Figure 6a, long voids surrounding slag stringers indicate that loading across the stringers has caused the iron to "peel way" from the slag. Figure 6b shows a fractured surface containing a large slag particle. Note the cracking in the particle and the presence of a crystalline phase.

\section{Conclusions}

Results from traditional metallography combined with image analysis on the Titanic wrought iron rivets suggest that the microstructure is extremely variable, most likely the result of the inconsistent quality of feedstock at the time, further influenced by the use of batches that were worked by a variety of puddlers. Also noteworthy is the variability of results among the Titanic rivets, supporting the idea that the processing, and therefore the quality of wrought iron, is dependant not only on the stock used, but also on the worker, or puddler, who mixes the batch. The microstructural characteristics observed indicate that the wrought iron was worked insufficiently and at too low of a temperature, resulting in large, coarse slag particles that act as sources for failure under sufficient load. Results of mechanical test confirm that when large amounts of slag are oriented perpendicular to the load, the slag particles act as sites for cracking and eventual failure. Detailed microfractography results suggest that this loss of strength is due to decohesion along the iron-slag interface. Considering the reorientation of slag particles observed in the Titanic rivet heads, the loss of strength at the junction of the head and rivet shaft may have been considerable, and most certainly played a role during her sinking.

\section{References}

1. Aston, J., E. B. Story. Wrought Iron: Its Manufacture, Characteristics and Applications. 2nd ed. (Pittsburgh, PA: A. M. Byers Company) 1939.

2. The Making, Shaping, and Treating of Steel. 9th ed. (Pittsburgh, PA: Herbick \& Held) 1971

3. Morgan, J. The Strength of Victorian Wrought Iron. Proceedings of the Institution of Civil Engineers-Structures and Buildings 1999:295-300.

4. Gordon, R. B. Strength and Structure of Wrought Iron. Archeomaterials 1998;2(2):109-137.

5. Thearle SJP. The Modern Practice of Shipbuilding in Iron and Steel. Vol. 1 (ed 2nd). London: William Collins, Sons and Co.; 1891.

For More Information: Additional details on the full forensic investigation forthcoming at www.csititanic.com 


\section{Soft Imaging System}

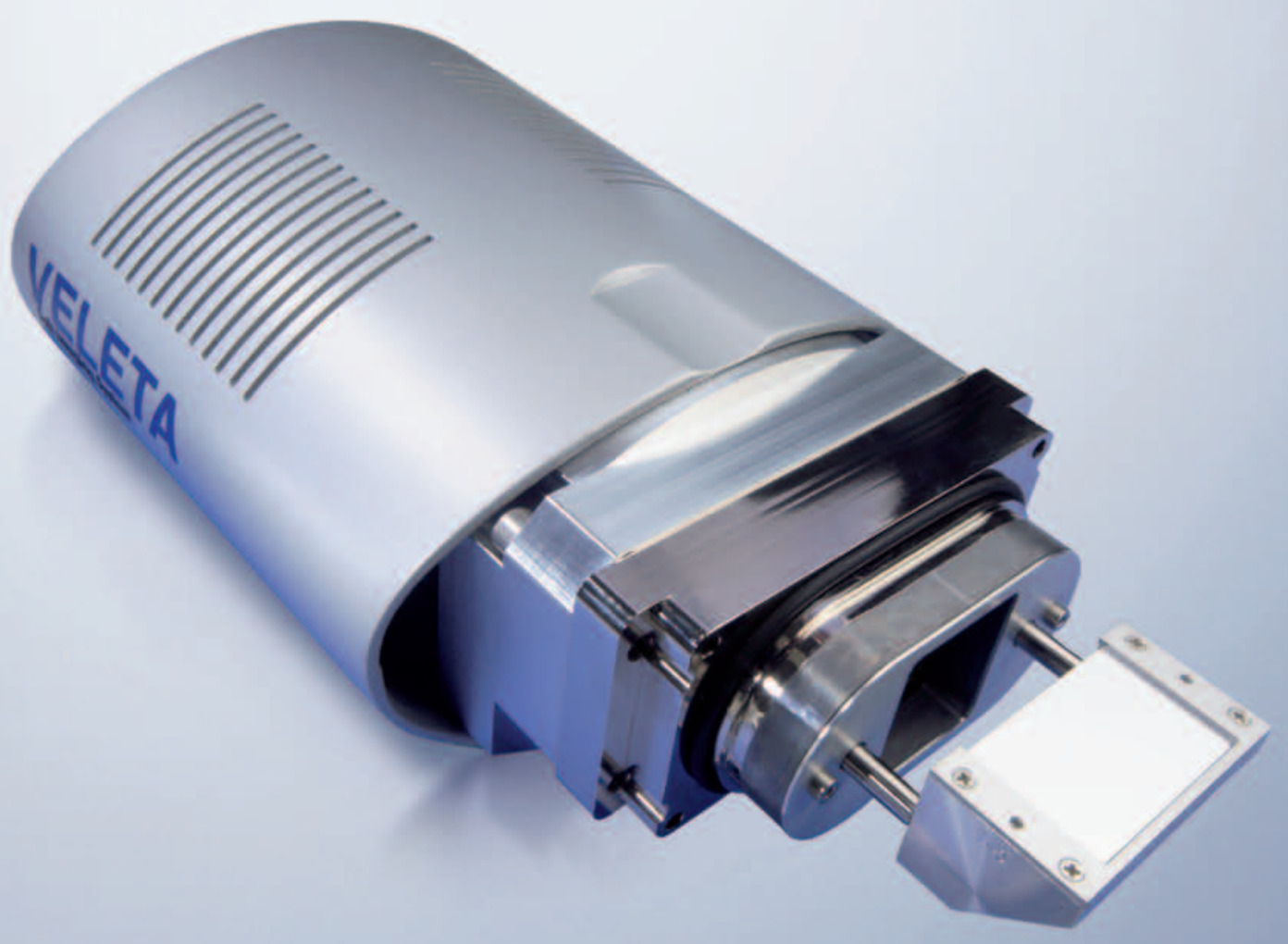

\section{YOUR SPECIFICATIONS - OUR SOLUTION VELETA - $2 \mathrm{k} \times 2 \mathrm{k}$ SIDE-MOUNTED TEM CAMERA SOLUTION}

Meeting the demands on today's TEM camera market - our new side-mounted TEM camera has the capabilities that customers are looking for in a $2 \mathrm{k} \times 2 \mathrm{k}$ camera. The new Veleta fills this description perfectly. If you're familiar with our MegaView III and Morada cameras, the Veleta's capabilities position it right between these two.

This new side-mounted TEM camera is our answer to the most current expectations on the TEM market. The Veleta is a Peltier-cooled camera featuring up to $2048 \times 2048$ highly sensitive pixels and has a 14-bit dynamic range. Veleta offers more than $10 \mathrm{fps}$ at full view and about 20 fps at binning mode 2 .

Veleta is optimized for today's latest applications - such as tomography or immunogold labeling. Naturally the camera is applicable for all standard TEM imaging tasks.

TEM - Cameras

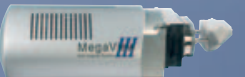

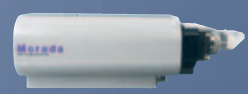

For detailed information please contact:

Olympus Soft Imaging Solutions

info.osis@olympus-sis.com

www.soft-imaging.net 